\title{
Procedure Agent Yes No Indicator
}

National Cancer Institute

\section{Source}

National Cancer Institute. Procedure Agent Yes No Indicator. NCI Thesaurus. Code

C162353.

An indication of whether procedure agent usage has occurred. 